\title{
ERRATA - 1
}

Para o Volume 1 - Número 03 da Revista Agrogeoambiental, nas páginas 107 e 109, as tabelas apresentadas com os títulos TABELA 2 e TABELA 3 possuem os títulos corretos, mas houve troca de tabelas.

Forma correta de apresentação:

\begin{tabular}{|c|c|c|c|c|c|c|c|c|c|c|}
\hline \multicolumn{7}{|c|}{ TABELA 2 - Página 107} & \multicolumn{4}{|c|}{ TABELA 3 - Página 109} \\
\hline \multirow{3}{*}{ Tratamento } & \multirow{3}{*}{$\begin{array}{l}\text { Profundidade } \\
\qquad(\mathrm{cm})\end{array}$} & $\begin{array}{l}\text { Areia } \\
\text { grossa }\end{array}$ & $\begin{array}{c}\text { Areia } \\
\text { fina }\end{array}$ & Silte & Argila & \multirow{5}{*}{$\begin{array}{l}\text { Classe } \\
\text { textural }\end{array}$} & Tratamento & $\varnothing 2 \mathrm{~mm}$ & $\frac{\varnothing 1 \mathrm{~mm}}{(\%)}$ & $\varnothing 0,5 \mathrm{~mm}$ \\
\hline & & \multirow{2}{*}{\multicolumn{4}{|c|}{ dak $/ \mathrm{kg}$}} & & \multicolumn{4}{|c|}{ LVAH - profundidade $0-30 \mathrm{~cm}$} \\
\hline & & & & & & & Mata & $51,72 \mathrm{~A}$ & $26,86 \mathrm{~A}$ & $11,04 \mathrm{~B}$ \\
\hline \multirow{2}{*}{\multicolumn{6}{|c|}{ LVAH }} & & Tradicional convencional & $70,44 \mathrm{~A}$ & $13,72 \mathrm{~B}$ & $4,31 \mathrm{~B}$ \\
\hline & & & & & & & Adensado orgânico & $71,68 \mathrm{~A}$ & $17,28 \mathrm{AB}$ & $4,86 \mathrm{~B}$ \\
\hline \multirow[b]{2}{*}{ Mata } & $0 / 30$ & 32,1 & 7,2 & 13,0 & 47,7 & Argila & \multicolumn{4}{|c|}{ LVAH - profundidade $30-60 \mathrm{~cm}$} \\
\hline & $30 / 60$ & 27,3 & 7,0 & 12,9 & 52,8 & Argila & \multirow{3}{*}{$\begin{array}{c}\text { Mata } \\
\text { Adensado convencional } \\
\text { Tradicional convencional } \\
\text { Adensado orgânico }\end{array}$} & $40,30 \mathrm{AB}$ & $29,00 \mathrm{~A}$ & $15,13 \mathrm{~A}$ \\
\hline \multirow{3}{*}{$\begin{array}{l}\text { Adensado } \\
\text { convencional }\end{array}$} & $0 / 30$ & 26,9 & 12,3 & 13,8 & 47,0 & Argila & & $\begin{array}{l}26,97 \mathrm{~B} \\
73,58 \mathrm{~A}\end{array}$ & $\begin{array}{l}28,04 \mathrm{~A} \\
11,15 \mathrm{~B}\end{array}$ & $\begin{array}{l}19,99 \mathrm{~A} \\
2,67 \mathrm{~B}\end{array}$ \\
\hline & & & & & & Muito & & $61,96 \mathrm{~A}$ & $20,75 \mathrm{AB}$ & $5,06 \mathrm{~B}$ \\
\hline & $30 / 60$ & 20,3 & 11,4 & 7,5 & 60,9 & Argiloso & \multicolumn{4}{|c|}{ LVA - profundidade $0-30 \mathrm{~cm}$} \\
\hline \multirow{2}{*}{$\begin{array}{c}\text { Tradicional } \\
\text { convencional }\end{array}$} & $0 / 30$ & 22,4 & 8,5 & 12,8 & 56,3 & Argila & \multirow{3}{*}{$\begin{array}{l}\text { Adensado convencional } \\
\text { Tradicional convencional } \\
\text { Adensado orgânico } \\
\end{array}$} & $\begin{array}{l}31,07 \mathrm{~B} \\
60,70 \mathrm{~A}\end{array}$ & $\begin{array}{r}29,36 \mathrm{~A} \\
21,34 \mathrm{AB}\end{array}$ & $\begin{array}{l}18,04 \mathrm{~A} \\
8,15 \mathrm{~B}\end{array}$ \\
\hline & $30 / 60$ & 20,0 & 8,1 & 13,3 & 58,6 & Argila & & $59,73 \mathrm{~A}$ & $\begin{array}{l}21,4 \mathrm{AD} \\
18,55 \mathrm{~B}\end{array}$ & $9,38 \mathrm{~B}$ \\
\hline \multirow{4}{*}{$\begin{array}{l}\text { Adensado } \\
\text { orgânico }\end{array}$} & \multirow{3}{*}{$0 / 30$} & \multirow{3}{*}{43,4} & \multirow{3}{*}{12,0} & \multirow{3}{*}{10,1} & \multirow{3}{*}{34,4} & Franco & & $68,37 \mathrm{~A}$ & $17,30 \mathrm{~B}$ & $4,43 \mathrm{~B}$ \\
\hline & & & & & & argilo & \multicolumn{4}{|c|}{ LVA - profundidade $30-60 \mathrm{~cm}$} \\
\hline & & & & & & arenoso & Mata & $22,09 \mathrm{~B}$ & $29,96 \mathrm{~A}$ & $21,12 \mathrm{~A}$ \\
\hline & $30 / 60$ & 32,4 & 11,8 & 12,8 & 49,1 & Argila & $\begin{array}{l}\text { Adensado convencional } \\
\text { Tradicional convencional }\end{array}$ & $\begin{array}{l}54,45 \mathrm{~A} \\
56,72 \mathrm{~A}\end{array}$ & $\begin{array}{l}22,42 \mathrm{AB} \\
23,06 \mathrm{AB}\end{array}$ & $\begin{array}{l}9,19 \mathrm{~B} \\
8,58 \mathrm{~B}\end{array}$ \\
\hline \multicolumn{7}{|c|}{ LVA } & Adensado orgânico & $67,92 \mathrm{~A}$ & $17,62 \mathrm{~B}$ & $4,29 \mathrm{~B}$ \\
\hline \multirow{2}{*}{ Mata } & $0 / 30$ & 30,4 & 14,8 & 15,0 & 39,9 & $\begin{array}{c}\text { Argila } \\
\text { arenosa }\end{array}$ & & & & \\
\hline & $30 / 60$ & 25,6 & 13,8 & 13,6 & 47,0 & Argila & & & & \\
\hline \multirow{2}{*}{$\begin{array}{l}\text { Adensado } \\
\text { convencional }\end{array}$} & $0 / 30$ & 35,5 & 13,3 & 12,1 & 39,1 & $\begin{array}{c}\text { Argila } \\
\text { arenosa }\end{array}$ & & & & \\
\hline & $30 / 60$ & 29,7 & 10,8 & 9,8 & 50,7 & Argila & & & & \\
\hline \multirow{2}{*}{$\begin{array}{c}\text { Tradicional } \\
\text { convencional }\end{array}$} & $0 / 30$ & 27,4 & 13,4 & 11,3 & 47,8 & Argila & & & & \\
\hline & $30 / 60$ & 20,7 & 11,6 & 10,0 & 57,3 & Argila & & & & \\
\hline \multirow{2}{*}{$\begin{array}{c}\text { Adensado } \\
\text { orgânico }\end{array}$} & $0 / 30$ & 19,2 & 10,1 & 11,0 & 60,0 & Argila & & & & \\
\hline & $30 / 60$ & 15,9 & 9,1 & 10,5 & 64,5 & $\begin{array}{l}\text { Muito } \\
\text { Argiloso }\end{array}$ & & & & \\
\hline
\end{tabular}




\section{ERRATA - 2}

Na edição Volume 1, Número 3 de dezembro de 2009, no Artigo “ANÁLISE DA PRECISÃO NO POSICIONAMENTO COM UM RECEPTOR GPS DE NAVEGAÇÃO”, na página 81, coluna da direita, último parágrafo, deve-se ler nas últimas 14 linhas:

Esta melhor situação é dada pelo valor do DOP (Dilution Of Precision) que, em conceito, envolve as posições dos satélites em determinado instante (SEGANTINE, 2005). Como as posições dos satélites mudam a todo instante, a precisão mínima para levantamentos geodésicos fica comprometida ao utilizar um GPS de navegação, uma vez que é impossivel registrar os "dados brutos" emitidos pelos satélites (código C/A elou fase da portadora), impossibilitando os cálculos para uma determinação mais acurada das coordenadas e conseqüente eliminação ou redução de diversos erros envolvidos no posicionamento GPS.

Ainda na página 81 , coluna da direita, $1^{\circ}$ parágrafo. Deve-se ler após o ponto seguido (Silva, 2006).:

Em outras palavras, consideram-se aleatórias por apresentarem diferentes graus de precisão. 


\section{ERRATA}

Informamos que na edição Volume 1 - Número 03 da Revista Agrogeoambiental, "houve um equívoco de informações nas páginas 107 e 109. As tabelas apresentadas com os títulos TABELA 2 e TABELA 3 possuem os titulos corretos, mas houve troca das tabelas (informações) no item resultados e discussão do artigo."

Forma correta de apresentação:

\begin{tabular}{|c|c|c|c|c|c|c|c|c|c|c|}
\hline \multicolumn{7}{|c|}{ TABELA 2 - Página 107} & \multicolumn{4}{|c|}{ TABELA 3 - Página 109} \\
\hline \multirow{3}{*}{ Tratamento } & \multirow{3}{*}{$\begin{array}{l}\text { Profundidade } \\
\qquad(\mathrm{cm})\end{array}$} & $\begin{array}{l}\text { Areia } \\
\text { grossa }\end{array}$ & $\begin{array}{l}\text { Areia } \\
\text { fina }\end{array}$ & Silte & Argila & \multirow{4}{*}{$\begin{array}{l}\text { Classe } \\
\text { textural }\end{array}$} & Tratamento & \multirow[t]{2}{*}{$\varnothing 2 \mathrm{~mm}$} & \multirow{2}{*}{$\frac{\emptyset 1 \mathrm{~mm}}{\frac{(\%)}{30 \mathrm{~cm}}}$} & \multirow[t]{2}{*}{$\emptyset 0,5 \mathrm{~mm}$} \\
\hline & & & & & & & LVAH - profundidade $0-30 \mathrm{~cm}$ & & & \\
\hline & & \multicolumn{4}{|c|}{ dak $/ \mathrm{kg}$} & & $\begin{array}{c}\text { Mata } \\
\text { Adensedo }\end{array}$ & $51,72 \mathrm{~A}$ & $26,86 \mathrm{~A}$ & $\begin{array}{l}11,04 \mathrm{~B} \\
23,75 \mathrm{~A}\end{array}$ \\
\hline \multicolumn{6}{|c|}{ LVAH } & & $\begin{array}{l}\text { Tradicional convencional } \\
\text { Adensado orgânico }\end{array}$ & $\begin{array}{l}70,44 \mathrm{~A} \\
71,68 \mathrm{~A} \\
\end{array}$ & $\begin{array}{r}13,72 \mathrm{~B} \\
17,28 \mathrm{AB} \\
\end{array}$ & $\begin{array}{l}4,31 \mathrm{~B} \\
4,86 \mathrm{~B} \\
\end{array}$ \\
\hline \multirow[b]{2}{*}{ Mata } & $0 / 30$ & 32,1 & 7,2 & 13,0 & 47,7 & Argila & \multicolumn{4}{|c|}{ LVAH - profundidade $30-60 \mathrm{~cm}$} \\
\hline & $30 / 60$ & 27,3 & 7,0 & 12,9 & 52,8 & Argila & Mata & $40,30 \mathrm{AB}$ & $29,00 \mathrm{~A}$ & $15,13 \mathrm{~A}$ \\
\hline \multirow{3}{*}{$\begin{array}{l}\text { Adensado } \\
\text { convencional }\end{array}$} & $0 / 30$ & 26,9 & 12,3 & 13,8 & 47,0 & Argila & Tradicional convencional & $\begin{array}{l}26,9 / \mathrm{B} \\
73,58 \mathrm{~A}\end{array}$ & $\begin{array}{l}28,04 \mathrm{~A} \\
11,15 \mathrm{~B}\end{array}$ & $\begin{array}{l}19,99 \mathrm{~A} \\
2,67 \mathrm{~B}\end{array}$ \\
\hline & \multirow{2}{*}{$30 / 60$} & \multirow{2}{*}{20,3} & \multirow{2}{*}{11,4} & \multirow{2}{*}{7,5} & \multirow{2}{*}{60,9} & Muito & Adensado orgânico & 61,96A & $20,75 \mathrm{AB}$ & $5,06 \mathrm{~B}$ \\
\hline & & & & & & Argiloso & \multicolumn{4}{|c|}{ LVA - profundidade $0-30 \mathrm{~cm}$} \\
\hline \multirow{2}{*}{$\begin{array}{c}\text { Tradicional } \\
\text { convencional }\end{array}$} & $0 / 30$ & 22,4 & 8,5 & 12,8 & 56,3 & Argila & \multirow{3}{*}{$\begin{array}{c}\text { Mata } \\
\text { Adensado convencional } \\
\text { Tradicional convencional } \\
\text { Adensado orgânico } \\
\end{array}$} & $60,70 \mathrm{~A}$ & $21,34 \mathrm{AB}$ & $8,15 \mathrm{~B}$ \\
\hline & $30 / 60$ & 20,0 & 8,1 & 13,3 & 58,6 & Argila & & $59,73 \mathrm{~A}$ & $18,55 \mathrm{~B}$ & $9,38 \mathrm{~B}$ \\
\hline \multirow{4}{*}{$\begin{array}{l}\text { Adensado } \\
\text { orgânico }\end{array}$} & \multirow{2}{*}{$0 / 30$} & \multirow{2}{*}{43,4} & \multirow[b]{2}{*}{12,0} & \multirow{3}{*}{10,1} & \multirow[b]{2}{*}{34,4} & \multirow{2}{*}{$\begin{array}{l}\text { Franco } \\
\text { argilo } \\
\text { arenoso }\end{array}$} & & \multicolumn{3}{|c|}{ LVA - profundidade $30-60 \mathrm{~cm}$} \\
\hline & & & & & & & Mata & $22,09 \mathrm{~B}$ & $29,96 \mathrm{~A}$ & $21,12 \mathrm{~A}$ \\
\hline & & & & & & & Adensado convencional & $54,45 \mathrm{~A}$ & $22,42 \mathrm{AB}$ & $9,19 \mathrm{~B}$ \\
\hline & $30 / 60$ & 32,4 & 11,8 & 12,8 & 49,1 & Argila & Tradicional convencional & $56,72 \mathrm{~A}$ & $23,06 \mathrm{AB}$ & $8,58 \mathrm{~B}$ \\
\hline & & LV & & & & & Adensado orgânico & $67,92 \mathrm{~A}$ & $17,62 \mathrm{~B}$ & $4,29 \mathrm{~B}$ \\
\hline Mata & $0 / 30$ & 30,4 & 14,8 & 15,0 & 39,9 & $\begin{array}{c}\text { Argila } \\
\text { arenosa }\end{array}$ & & & & \\
\hline & $30 / 60$ & 25,6 & 13,8 & 13,6 & 47,0 & Argila & & & & \\
\hline Adensado & $0 / 30$ & 35,5 & 13,3 & 12,1 & 39,1 & $\begin{array}{c}\text { Argila } \\
\text { arenosa }\end{array}$ & & & & \\
\hline convencional & $30 / 60$ & 29,7 & 10,8 & 9,8 & 50,7 & Argila & & & & \\
\hline Tradicional & $0 / 30$ & 27,4 & 13,4 & 11,3 & 47,8 & Argila & & & & \\
\hline convencional & $30 / 60$ & 20,7 & 11,6 & 10,0 & 57,3 & Argila & & & & \\
\hline Adensado & $0 / 30$ & 19,2 & 10,1 & 11,0 & 60,0 & Argila & & & & \\
\hline orgânico & $30 / 60$ & 15,9 & 9,1 & 10,5 & 64,5 & $\begin{array}{l}\text { Muito } \\
\text { Argiloso }\end{array}$ & & & & \\
\hline
\end{tabular}

